\title{
LAS VÍAS DE ACCESO AL PODER LOCAL EN LA VALENCIA DEL SIGLO XVIII. CONTINUIDAD Y CAMBIO DE UN PROCESO DE ENNOBLECIMIENTO DE LOS OFICIOS MUNICIPALES
}

\author{
Por Encarna GARCÍA MONERRIS \\ Departamento de Historia Contemporánea \\ de la Universidad de Valencia
}

\section{INTRODUCCIÓN}

La abolición de los fueros en 1707, y el establecimiento de la Nueva Planta ${ }^{(1)}$, como marco jurídico a partir del cual se iba a dotar de contenido a las instituciones valencianas, introdujo cambios cualitativos en lo que venía siendo el devenir histórico del poder local. Supuso, al mismo tiempo, la concreción de una nueva dinámica en las relaciones de la Monarquía con las distints instancias o niveles de poder existentes. Uno de ellos era el municipio y, especialmente, el municipio foral.

Del conjunto de transformaciones de que fue objeto este último, quisiéramos referirnos aquí a los mecanismos de cooptación del personal político a escala local, a través de un análisis no ya de la nueva oligarquía urbana valenciana, sino de quienes a lo largo del siglo XVIII intentaron llegar a formar parte de ella. Los memoriales de los pretendientes a plazas de regidor y la documentación que les acompaña nos ha permitido conocer qué sectores sociales se mostraron dispuestos a participar de la nueva organización política de la Monarquía. Una organización que, tal y como ha resaltado Fernández Albaladejo, está al servicio de los intereses de la nobleza territorial, y de «otros intereses no menos representativos de la constitución estamental»; pero, fundamentalmente, al servicio de los intereses dinásticos ${ }^{(2)}$.

Para poder delimitar el grado de continuidad o ruptura que implicó la uniformización legislativa del siglo XVIII, consideramos necesario hacer alguna referencia al municipio foral valenciano. Concretamente a su configuración cam- 
biante a lo largo del tiempo, producto de modificaciones y/o innovaciones forales, estrictamente hablando.

\section{LA PRESENCIA DEL ESTAMENTO NOBILIARIO EN EL GOBIERNO FORAL DE VALENCIA}

Hace ya algunos años, Belenguer Cebriá, en su estudio sobre la Valencia del siglo XV, nos hablaba de la pérdida gradual de «autonomía» que sufre el gobierno de la ciudad como correlato de la cada vez mayor injerencia de la autoridad real en el mismo ${ }^{(3)}$. Las relaciones traumáticas o amistosas Monarquía-ciudad y las pugnas existentes en el seno de los grupos dominantes urbanos u oligarquías locales estarían en la base de este proceso. Son precisamente estos dos hechos, íntimamente relacionados, los que obligan a efectuar unas matizaciones respecto al carácter del municipio foral.

En primer lugar, y sin ánimo de establecer ningún tipo de prioridad, calificar de «democráticos» a sus órganos gestores implicaría no sólo un anacronismo conceptual, sino también desconocer el grado de representatividad de esa institución en relación al conjunto de la población presuntamente representativa ${ }^{(4)}$. Una institución que en absoluto es ajena al entramado estamental y jerárquico de la sociedad del Antiguo Régimen, sino que se nutre del mismo y que refleja, en buena medida, los cambios que se operan en dicha sociedad, y, particularmente, en las clases privilegiadas. La «libertad» foral, de cuya pérdida tanto se lamentó el municipalismo romántico ${ }^{(5)}$, es, en este sentido, susceptible de revisión, considerando siempre el marco jurídico-político en el que se inscribe; esto es, presidido por el privilegio, como «ordenamiento jurídico de carácter desigual en el orden civil», y caracterizado por un poder político disperso en potestades particulares ${ }^{(6)}$.

La segunda observación tiene que ver con el concepto de «autonomía» municipal. Una autonomía que sufre un proceso de decadencia y que, por consiguiente, debe relativizarse. Pero, sobre todo, porque, tal y como ha señalado García Fernández, se trata de un concepto al que no se le puede dar una «acepción anacrónica», sino que, en cada momento histórico, responde a supuestos jurídicos y políticos diferentes ${ }^{(7)}$. Si tuviéramos que buscar un sujeto histórico responsable de esa decadencia o pérdida del grado de autonomía municipal, no podríamos apelar, sin más, al autoritarismo real. Los intereses de las oligarquías urbanas y, lo que es más, las pugnas o conflictos internos de las mismas desempeñaron también un papel protagonista. De ahí que nos refiriéramos a las relaciones ciudadMonarquía para explicar los cambios operados en el gobierno valenciano de la época foral, y que afectarán tanto a sus competencias como a la composición de sus órganos gestores. En esto último es en lo que queremos incidir; concretamente en la composición social de los llamados jurats.

De 1245 hasta 1321, los cuatro miembros que componían esta alta magistratura municipal en Valencia debían ser "ciudadanos honrados» ${ }^{(8)}$. A partir de 1321 su número se amplía a seis, al tiempo que se da entrada en el gobierno de 
la ciudad a miembros del estamento nobiliario. Dos de esas seis plazas quedaban destinadas a los «caballeros» y «generosos», es decir, a la nobleza no titulada (9). El hecho es doblemente significativo. En primer lugar, la ampliación no tiene en cuenta a la menestralía, que nunca tuvo una representación entre los jurados. En segundo lugar, la presencia, por primera vez, de la nobleza menor en el Ayuntamiento inicia lo que puede considerarse como el proceso de aristocratización del gobierno municipal en Valencia. Al igual que en Cataluña ${ }^{(10)}$, dicho proceso no tiene su punto de partida en el siglo XVIII, sino que es anterior. Pero quizá lo más interesante sea destacar que esa aristocratización se presenta unida a otros dos hechos no lejanos en el tiempo: el inicio de la pérdida de autonomía municipal, y la mayor injerencia real en el gobierno de la ciudad, especialmente perceptible a partir del siglo XV ${ }^{(11)}$.

El incremento de la autoridad de los jurados, la pérdida de «libertad» del Consell General y la intensificación del control del monarca sobre los primeros se volverá irreversible en 1418, cuando Alfonso el Magnánimo introduzca innovaciones en el sistema de elección del cuerpo municipal. Hasta ese momento, y desde 1283, los jurados salientes de cada año y los 48 consellers, representantes de las doce parroquias de la ciudad (quedaban fuera, por tanto, los consellers de los oficios, institucionalizados, precisamente, en 1283), nombraban 12 candidatos (uno por parroquia), de los que se sorteaban los jurados del año siguiente.

El mecanismo instaurado por Alfonso el Magnánimo era en apariencia idéntico, si bien introducía una modificación sustancial: la designación de los 12 candidatos era competencia del monarca. En la práctica, sin embargo, la lista sería elaborada por el racional. Se trataba de un nuevo cargo municipal, encargado de las finanzas de la ciudad e introducido poco antes de que empezase a funcionar la «Ceda», que era el nombre que recibía el sistema de elección descrito. En cuanto al Consell General, sus miembros serían elegidos, desde ese momento, por los jurados, junto al racional, síndico y abogados de la ciudad ${ }^{(12)}$.

En consecuencia, sería en el contexto de este intervencionismo regio, directo o indirecto, en el que se inscribiría la negativa del monarca a conceder la insaculación a la ciudad de Valencia en 1482, cuando de hecho se estaba concediendo a otras ciudades. Respecto a este otro método de elección de los cargos municipales, recientes investigaciones han puesto de relieve que su significado y trascendencia, en el ámbito del municipio foral de la antigua Corona de Aragón, no son unívocos. Que no puede definirse, sin más, como una forma de manifestarse el autoritarismo de la Monarquía, mediante una mayor injerencia en los gobiernos locales ${ }^{(13)}$. En última instancia, serían las relaciones ciudad-Monarquía, en cada caso concreto, las que expliquen las causas y fechas que conducen a la adopción del sistema insaculatorio. Belenguer Cebriá compara la actitud real frente a Barcelona, con la mantenida en Valencia, indicando que:

«On, cas de Barcelona, els rectors municipals havien mantingut un cert grau d'autonomia, la insaculació comportaria, evidentment, una mesura d'enfortiment reial (...). En canvi, en els indrets, com ara Va- 
lència, on l'elecció dels jurats depenia directament del rei (...) la insaculació representava, amb tots els obstacles que hom vulgui, un lleuger automonisme comunal respecte a la monarquia» (14).

La cuestión, sin embargo, no puede reducirse a la previa existencia, o no, de un mayor o menor intervencionismo real. Las particularidades de cada gobierno local y de su oligarquía tuvieron un peso decisivo, hasta el extremo de que la insaculación no siempre supuso un éxito rotundo y exclusivo del monarca. Torras i Ribé se muestra más partidario de recurrir a la «dinámica interna» del municipio para explicar la introducción del nuevo sistema, el cual, a su juicio, «respon a un determinat grau de la complexitat de la vida municipal i és un sistema que en molts aspectes regularitza aquesta vida municipal» ${ }^{(15)}$.

En Valencia los problemas de orden público y el bandolerismo repercutían de forma casi directa en el gobierno de la ciudad ${ }^{(16)}$. La petición del privilegio insaculatorio efectuada en el siglo XVII conectaba, de este modo, con los intereses de un sector de la oligarquía urbana, deseosa de garantizar su presencia en el Ayuntamiento. Casey señala al respecto que «els valencians volien una insaculació própia pera protegirse del caprici del rei i constituir-se en una oligarquia estable» ${ }^{(17)}$. Dicha estabilidad vendría dada, en teoría, por la existencia de listas de insaculados (dos de ciudadanos y una de caballeros y generosos); sólo de entre éstos se efectuaría el sorteo de los oficios. Sin embargo, como el mismo Casey describe, si el sistema «condujo a una reducción de la base de reclutamiento en el siglo XVII, dio también la oportunidad a las autoridades reales de intervenir cada vez más en los nombramientos para los cargos ${ }^{(18)}$. Es decir, que la injerencia real continúo siendo un hecho.

En este juego de intereses, las necesidades hacendísticas de la Monarquía contribuyeron, en buena medida, a dar el placet a la petición de Valencia ${ }^{(19)}$. La entrega del privilegio insaculatorio en febrero de 1634 sancionaba lo que se ha denominado «contrato entre la oligarquía y el rey», en el que éste, a cambio de defender los privilegios de aquélla obtendría servicios ${ }^{(20)}$.

No obstante, hasta 1648 Valencia no obtuvo definitivamente la insaculación. La crisis social y política que atravesaba y la derogación del privilegio de 1634 por el virrey llevaron a una segunda concesión, en la que el monarca introducía elementos ausentes en $1634^{(21)}$. No vamos a entrar aquí en un análisis de los privilegios de insaculación concedidos a Valencia. Simplemente queremos destacar que en el de 1648, en el capítulo II, el rey se reserva la posibilidad de aumentar el número de insaculados por bolsa, pudiendo oscilar entre 20 ó 30, «como pareciere á su Magestad, según las ocasiones y tiempos, y sugetos que se ofrecieran para estar en ellas»" (22).

Puede decirse, por tanto, que la insaculación de 1648 fue restrictiva de los intereses iniciales de la ciudad. Lejos de reducirse al máximo la élite gobernante, las modificaciones introducidas por el monarca le permitieron a éste una mayor intervención y control sobre quiénes debían formar parte de aquélla: primero, doblando el número de propuestos por la ciudad y, luego, dejando a su libre albe- 
drío la posibilidad de nombrar a personas que no estuvieran incluidas a priori en dicha propuesta. Ello permitiría «una infusió constant de ciutadans i cavallers nous, els quals reflectien, sense dubte, la composició econòmica i intelectual de la seua classe» (23).

Junto a la insaculación, otro de los cambios que afectarán al gobierno de la ciudad de Valencia en el siglo XVII será, precisamente, la entrada al mismo de la nobleza titulada. En 1652 serían insaculados por primera vez tres títulos en la bolsa de caballeros, figurando como jurat en cap de ese año el conde del Real ${ }^{(24)}$.

En el setecientos confluyen, pues, dos hechos de especial significación. Por un lado, el acceso de la nobleza titulada al ayuntamiento foral; y, por otro, la concesión misma del privilegio insaculatorio, como forma de elección de los cargos de jurado. El primero contribuye a acrecentar el carácter aristocrático del gobierno municipal valenciano. El segundo garantiza la continuidad del intervencionismo real en el mismo.

Por lo expuesto hasta aquí, creemos que el estudio de los mecanismos de elección de los oficios municipales se inscribe en una problemática más amplia que afecta a la propia organización política de la Monarquía, a sus relaciones con las élites gobernantes y, cómo no, a la organización política de las ciudades. La Nueva Planta comportará sustanciales modificaciones impuestas desde arriba, pero con el beneplácito de un amplio sector de la clase dominante, a quien el nuevo régimen municipal abrirá sus puertas. La dialéctica centralización-aristocratización, apreciable desde tiempo atrás, entraría por nuevos cauces a partir de 1707 .

\section{LA CONFIGURACIÓN DEL AYUNTAMIENTO POSTFORAL}

Como apuntamos al principio de estas líneas, la reorganización institucional de que fue objeto el País Valenciano, al quedar abolida la legalidad foral, afectó de manera muy concreta al gobierno municipal. Con la Nueva Planta, las leyes castellanas impregnaron lo que iba a ser el organigrama político de la Monarquía en unos territorios que, hasta ese momento, se habían regido mediante normas propias y específicas. El proceso, aunque rápido, no estuvo exento de problemas derivados, en parte, del grado de experimentación que suponía imponer, de forma súbita y rotunda, una legislación ajena por completo al viejo orden foral, y que implicaba la derogación de este último. Por su parte, el hecho de que la guerra continuara en los otros países de la antigua Corona aragonesa debió de imprimir a la reorganización valenciana un cierto cariz de imprecisión y apresuramiento, fruto de la necesidad de legitimar, cuanto antes, el proyecto político de la nueva dinastía borbónica ${ }^{25)}$.

Con todo, y a pesar de lo dicho, los cambios no quedarían mínimamente perfilados hasta después de concluida la Guerra de Sucesión. Así, por ejemplo, la división político-administrativa del territorio en Corregimientos no llegó a consumarse hasta bien avanzada la centuria: los problemas derivados de las competen- 
cias de jurisdicción entre las distintas autoridades, el carácter que se debía dar a cada Corregimiento (civil o militar), y los obstáculos de índole territorial y personal estuvieron, en suma, en la base de esta demora ${ }^{(26)}$.

En la esfera estrictamente local, los nuevos Ayuntamientos tenían que configurarse según el modelo castellano y, lo que es más importante, con individuos cooptados entre los de probada lealtad a la recién instaurada Monarquía. La operación no resultaba nada fácil, según se desprende de la propuesta enviada por el presidente de la Chancillería, Pedro de Larrategui y Colón, al secretario del rey, el 6 de diciembre de 1707. Larrategui veía conveniente que fuesen los mismos corregidores, una vez establecidos, quienes efectuasen la propuesta de individuos aptos para la nueva planta municipal, dado que:

«El número de Rexidores que podrá ponerse en cada Ciudad, Villa y Lugar, y la calidad de los sugetos aptos para estos empleos, tiene mucha dificultad el poder hacer yo desde aquí prompta y firme proposición; porque como el número ha de corresponder á las poblaciones, que son tantas y tan diversas en la vecindad. Y la calidad de los sugetos pide tanto examen oy; era preciso para lograrlo consumir mucho tiempo; y para adquirir las noticias de fuera embaraza mucho lo intransitable de los caminos por muchas partes del Reyno, parte por la vecindad de los enemigos; y parte, por las insolencias de los Miqueletes. A que se añade que hasta que se resuelban los Correximientos y se les señale a cada uno un territorio, no puede saverse qué poblaciones quedan como Aldeas, sólo con Justicias Pedáneas; y quáñes han de quedar como Villas con la Jurisdicción Ordinaria; y esta distinción parece preciso lo sea también para la calidad de su Govierno ${ }^{(27)}$.

La actuación del monarca para nada tuvo en cuenta la opinión del presidente de la Chancillería. El día 12 del mismo mes comunicaba a la Cámara de Castilla el nombramiento de los 32 regidores que debían formar el Ayuntamiento de Valencia ${ }^{(28)}$. Tan sólo habían transcurrido ocho meses desde que las tropas borbónicas hicieran su entrada en ella. Desde entonces, y hasta enero de 1708, el gobierno de la ciudad había cambiado en dos ocasiones, aunque en ambas según el antiguo sistema de jurados, y con claro carácter de provisionalidad ${ }^{(29)}$. A partir de 1708 la innovación se torna irreversible, y Valencia pasa a ser gobernada por un corregidor, dos alcaldes mayores y treinta y dos regidores. Todos ellos nombrados por el propio monarca.

Desde 1718 , el cargo de corregidor iría unido al de intendente ${ }^{(30)}$, hasta que quedaron desvinculadas ambas competencias en $1766^{(31)}$, si bien, en Valencia, esto último se produciría en $1770^{(32)}$. En un principio, y durante bastantes años, sus atribuciones abarcarían materias tales como hacienda, guerra, justicia y policía.

Los alcaldes mayores, junto con el intendente-corregidor, eran los encargados de administrar justicia y de gobernar en lo económico y en lo político, debiendo presidir los Ayuntamientos en ausencia del segundo. Hasta la Ordenanza 
de Intendentes y Corregidores de 13 de octubre de 1749 su nombramiento era competencia del corregidor. A partir de ese momento, el monarca se adjudica tal atribución, previo conocimiento de una terna propuesta por la Cámara de Castilla ${ }^{(33)}$. La duración de estos cargos fue trienal hasta la Real Cédula de 21 de abril de 1783 , en que se estableció en seis años ${ }^{(34)}$.

Respecto a los regidores - personal que más nos interesa destacar-, tal y como hemos dicho, su número fue, en un principio, de $32{ }^{(35)}$. Años más tarde, en 1736, tras alguna sugerencia hecha al respecto por la Cámara de Castilla y la Audiencia de Valencia ${ }^{(36)}$ quedaron reducidos a 24: 16 continuarían como regidurías de la clase de caballeros y 8 como regidurías de la clase de ciudadanos. Todas ellas de carácter vitalicio y de nombramiento real (37). En 1739 se introduce un cambio cualitativo en este nivel del gobierno municipal: el desgobierno en que se venía sumiendo el Ayuntamiento de Valencia ${ }^{(38)}$, a pesar del crecido número de regidores, y las necesidades financieras de la Monarquía llevan a ésta a poner en práctica la enajenación por juro de heredad de estos oficios ${ }^{(39)}$. Así, entre 1739 y 1743 fueron vendidas doce plazas de regidor, por un precio cada una que osciló entre los 30.000 y los 33.000 reales de vellón ${ }^{(40)}$. De este modo, la mitad de las regidurías pasaron a ser propiedad de un número reducido de familias, en cuyo seno se va sucediendo el oficio. En algunos casos, no obstante, y bastante tardíamente, fueron objeto de compra-venta entre particulares, como si de una mercancía se tratara. La operación económica que ello suponía proporcionó a los vendedores ciertos beneficios, por cuanto el precio de venta duplicaba el precio inicial de compra. Ahora bien, en los casos registrados hemos podido observar que, muchas veces, el dinero obtenido era utilizado para saldar deudas, contraídas, entre otros, con el que iba a ser el nuevo propietario de la plaza de regidor ${ }^{(41)}$.

Quiénes ocuparon las regidurías del Ayuntamiento de Valencia en el siglo XVIII no es el objeto de estas páginas ${ }^{(42)}$. Queremos ocuparnos, por el contrario, de aquellos que las pretendieron y de los mecanismos que su dotación comportaba en dicha centuria. Pero antes de entrar en ello, es necesario detenerse mínimamente en una cuestión que reviste gran importancia para definir el carácter de «clase» de lo que va a ser la nueva oligarquía municipal. Nos referimos a la naturaleza de las plazas de regidor: su división en «nobles» y «ciudadanos» predeterminará qué individuos son susceptibles de llegar a formar parte de dicha oligarquía.

Al hablar del gobierno de la ciudad en la época foral, indicamos someramente caáles habían sido el número de jurados y las clases que se repartían las seis magistraturas: cuatro los ciudadanos y dos los caballeros o nobles. Indicamos también que la inclusión, en 1321, de los dos miembros pertenecientes al estamento militar iniciaba un proceso de aristocratización, que se vería reforzado en 1652 con la entrada, en la bolsa de insaculados de dicho estamento, de la nobleza titulada. Pues bien, con la Nueva Planta, esta proporción entre ciudadanos y caballeros se vio alterada en favor de los segundos: hasta 1736 , el 75 por 100 de las 
plazas pasa a manos de la nobleza, en un sentido genérico - desde hidalgos a títulos del Reino-, y a partir de esa fecha el porcentaje disminuye a un 66,6 por 100. Es decir, que a pesar de la reducción del número de regidurías a 24 , dos tercios continúa en manos del estamento nobiliario. Por consiguiente, puede hablarse del ordenamiento jurídico castellano como el marco legal que introdujo un cambio brusco y cualitativo en la composición de las instituciones locales, acentuando su carácter aristocrático.

Ahora bien, de manera similar a lo ocurrido en la época foral, esas instituciones pierden el grado de "relativa autonomía» en que se venían gobernando, limitándose la capacidad de gestión política y económica de sus nuevos miembros. Y ello porque la abolición de los fueros se inscribía en un amplio programa político, en el que la centralización administrativa era el corolario de la unificación legislativa. Las competencias conferidas al intendente-corregidor en materia de rentas y abastos, por ejemplo, convierten a los regidores en meros subalternos, sujetos a la autoridad del delegado real.

Aunque con modificaciones, la división de las regidurías en pertenecientes a nobles y ciudadanos perpetuó la ya existente durante el gobierno foral. Al menos, así se desprende de las palabras del monarca, cuando nombró al primer Ayuntamiento borbónico:

«Y teniendo por conveniente haya algunos de orden de ciudadanos (...) nombro ocho con el nombre de Regidores Ciudadanos, y no con otro..." (44).

En este hecho debió de apoyarse el Ayuntamiento de Valencia, cuando, en sus informes a propósito de plazas vacantes, insistía en afirmar que los nuevos regidores eran «subrogados de los antiguos Jurados» ${ }^{(45)}$, y quienes pasasen a ocupar este oficio debían tener «las circunstancias que previenen las Leyes del Reyno»; esto es, las leyes castellanas. Pero en aquellos casos en los que dichas leyes no especifican nada, como ocurre con las cualidades que deben tener los ciudadanos para ocupar estas plazas, «parece será muy conveniente conformarse con las que loablemente se observaban en tiempo del Gobierno pasado» ${ }^{(46)}$. Esto es, conforme a lo prevenido por los fueros ${ }^{(47)}$.

La composición del Ayuntamiento valenciano, tal y como la hemos expuesto, se mantuvo hasta el final del Antiguo Régimen, a pesar de los intentos por convertir todas las regidurías a una sola clase, la de nobles ${ }^{(48)}$. Sin embargo, si tenemos en cuanta la Real Cédula de 14 de agosto de $1724^{(49)}$, puede decirse que la división ciudadanos-nobles permaneció de una manera ficticia. De haberse aplicado estrictamente esta última, se hubiera modificado sustancialmente la naturaleza de las ocho plazas de regidor que correspondían a los primeros: si para cubrir una vacante de esta clase los pretendientes debía acreditar que descendían de ciudadanos de inmemorial o de insaculados, desde 1724, y conforme a la citada Real Cédula, ello implicaba que pertenecían al estamento militar, puesto que habían sido homologados a los hidalgos castellanos de sangre y solar conocido y a los hidalgos de privilegio, respectivamente ${ }^{(50)}$. Es decir, que eran nobles, aun- 
que ocuparan unas plazas que recibían una denominación distinta. Sólo a la altura de 1792, el Ayuntamiento propondría al monrca, sin ningún éxito, que todas las regidurías se consideraran de la clase de nobles, concediéndose sin distinción a nobles, caballeros y generosos, o a "Ciudadanos de inmemorial, ó descendientes de insaculados en tiempo del antiguo Govierno (...) que por ello tenían verdadero goze de Hidalguía...» ${ }^{(51)}$.

En suma, sería a este Ayuntamiento de regidores «caballeros» y «ciudadanos» al que intentaría entrar, a lo largo del siglo XVIII, un número considerable de pretendientes, dispuestos a aceptar las líneas básicas de actuación del reformismo borbónico y del centralismo monárquico. No todos, lógicamente, vieron realizado su deseo, pero quienes lo consiguieron pasaron a formar parte de una nueva oligarquía ennoblecida o dispuesta a ennoblecerse. Algunos de sus miembros sobrevivirían sin grandes traumas el proceso revolucionario burgués decimonónico. Apellidos célebres como Rodríguez de la Encina, Musoles, etc., se perpetuarán en la sociedad liberal sin oponer una firme resistencia a los cambios que se iban a producir.

\section{EXPECTATIVAS POLÍTICAS Y VÍAS DE ACCESO AL PODER MUNICIPAL}

La insaculación, como método de proveer los cargos municipales quedó extinguida con la Nueva Planta. Para alcanzar el nuevo empleo de regidor, de nombramiento real, los pretendientes deberían, como primer requisito, optar a la pla$\mathrm{za}$. Antes de obtenerla se exigiría, no obstante, un curso legal que comenzaba siempre por la elaboración de memoriales. Estos serían remitidos al monarca pasando previamente un cedazo institucional; esto es, una especie de criba o preselección por parte de la Audiencia y de la Cámara de Castilla. Esta última, a partir de la información suministrada por aquélla, presentaba una terna por plaza vacante al rey, decidiendo éste finalmente. La elección recaía usualmente en uno de los propuestos, aunque en ocasiones también eran seleccionados pretendientes que no figuraban en la terna. Cuando esto último ocurría, no se apelaba en la medida en que el monarca era el que desestimaba o admitía a los pretendientes. Su decisión era ciertamente la última.

En este proceso la rapidez no era precisamente el elemento a destacar. $\mathrm{Cu}$ brir una plaza vacante por muerte de su titular costaba en el mejor de los casos un plazo de tiempo mínimo de un año. El curso seguido por los memoriales podemos detallarlo minuciosamente:

1.-Los interesados remitían sus memoriales al monarca.

2.-El rey los tramitaba a la Cámara de Castilla.

3.-La Cámara, a su vez, los pasaba a la Audiencia para que evacuase los informes requeridos.

4. - La Audiencia emitía, efectivamente, una información detallada de cada uno de los individuos que optaban a la vacante, valoran- 
do la veracidad de los méritos que alegaban y estableciendo una especie de baremo singular implícito, en el que unos eran desestimados y otros recomendados como más idóneos para el cargo.

5.- La Cámara de Castilla, en concreto la Secretaría de Gracia y Justicia, recibía toda la documentación elaborada, haciendo propio habitualmente el informe de la Audiencia.

6.-La Secretaría de Gracia y Justicia los remitía, a su vez, a la Cámara, que realizaba la denominada «consulta», y elaboraba la terna que transmitía al monarca para la elección definitiva.

Sin embargo, este proceso se complicaba en algunas ocasiones. Si ninguno de los componentes de la terna era considerado merecedor de la plaza, por orden del rey y a través de la Cámara se pedía a la Audiencia que propusiera a individuos que estimase idóneos y que no hubiesen sido pretendientes. Se iniciaba así, de nuevo, el camino recorrido con anterioridad por aquellos que habían enviado memoriales.

A partir de la década de los sesenta, y más concretamente desde 1765 , en el volumen de documentación que acompaña la provisión de cada una de las regidurías aparece de forma sistemática un nuevo informe: el dictamen elaborado por el Ayuntamiento a petición de la Audiencia. De este modo, los trámites a seguir descienden un eslabón más en la jerarquía política. Son dos los regidores a quienes el mismo Ayuntamiento comisiona para que estudien los distintos memoriales y valoren a los pretendientes. Lo habitual suele ser la reproducción aseṕtica de los méritos aducidos por los firmantes, y, en el mejor de los casos, la inclinación favorable hacia el que, a su juicio, era el más idóneo. A partir de aquí, la vía a seguir era la misma: Audiencia, Secretaría de Gracia y Justicia, Cámara de Castilla y monarca.

Sólo en ocasiones se piden informes particulares sobre uno o varios de los pretendientes al intendente o al inquisidor general. Es la opinión de este último la que va a ejercer una mayor influencia en la elección final, sobre todo cuando la recomendación es singular.

Por último, conviene subrayar el hecho de que la prelación y los informes que establece la Audiencia son normalmente aceptados por la Cámara; pero la decisión de ésta no predetermina necesariamente la del monarca. Cuando no existe coincidencia entre las diversas instancias, de inmediato se suscitan dudas sobre los propuestos y la provisión de las plazas se demora aún más con nuevos informes.

Un análisis sociológico de los pretendientes a regidor en la Valencia del siglo XVIII nos puede revelar, en este sentido, las vías normales de acceso de la oligarquía urbana a la esfera política local en el período borbónico. Con este estudio nos será sencillo comprender los modos y maneras de cooptación del personal político, el grado de participación de los distintos grupos sociales en una ciudad de Antiguo Régimen, y las cualidades requeridas o manifestadas para el ejercicio de los empleos municipales. En el fondo, el análisis no nos proporciona una radiografía exhaustiva de la sociedad valenciana del setecientos, pero sí que nos descu- 
bre algunas de las características esenciales de la articulación política urbana del feudalismo tardío. Es ésta una sociedad en descomposición que procura ensayar nuevas formas de reordenación política en las que se trata de dar entrada y de asimilar a grupos sociales de formación aún inestable ${ }^{(52)}$. Veámoslo más detenidamente.

\section{1.-El número de pretendientes}

Entre 1714 y 1800 se presenta en la ciudad de Valencia un total de 263 pretendientes a plazas de regidor ${ }^{(53)}$. En conjunto, puede decirse que se trata de un número considerable, teniendo en cuenta que el cargo era vitalicio y que, desde 1739 , doce de las veinticuatro plazas son perpetuas o por juro de heredad. De este modo, del total de regidurías, tan sólo la mitad era susceptible de ser ocupada por nuevos individuos mẹdiante el procedimiento ya descrito de la opción personal.

Esos 263 pretendientes se reparten de forma desigual a lo largo de la centuria. Así, durante la primera mitad, la media por vacante suele oscilar entre dos y seis individuos aproximadamente, mientras que desde 1749 hasta 1800 es de trece. Como se puede apreciar, la inflexión en la segunda mitad es evidente, mostrando, por lo general, una tendencia creciente que podríamos relacionar con una mayor estabilidad del nuevo régimen municipal. Asimismo, es lógico suponer que el cambio de coyuntura ${ }^{(54)}$ favoreció la incorporación de nuevos agentes urbanos - de origen agrario muchos de ellos- al poder local. La crisis finisecular no impidió, tal y como hemos podido comprobar, que las vacantes producidas fueran pretendidas por un considerable número de individuos: en 1782, dieciséis; en 1784, dieciocho; en 1786, veintiuno; y, finalmente, en 1793, veinte ${ }^{(55)}$. Tan sólo en seis vacantes no se alcanzó la media de trece, concentrándose la menor cantidad en 1799 , en que únicamente se presentaron cuatro ${ }^{(56)}$. Por otra parte, aunque no es generalizable, suele ocurrir que un mismo individuo pretenda varias veces y a vacantes distintas, hasta conseguir o no la plaza. La cuantificación de este último aspecto arroja el siguiente porcentaje para el período señalado:

\section{PRETENDIENTES A PLAZAS DE REGIDOR DEL AYUNTAMIENTO DE VALENCIA (1714-1800)}

\begin{tabular}{|c|c|c|}
\hline NÚM. VECES QUE PRETENDE & NÚM. PRETENDIENTES & $\%$ RESPECTO TOTAL \\
\hline 1 & 173 & 65,77 \\
2 & 57 & 21,67 \\
3 & 27 & 9,88 \\
4 & 6 & 2,28 \\
9 & 1 & 0,38 \\
\hline
\end{tabular}

Elaboración propia a partir de las fuentes citadas en la nota (52). 
Hasta la segunda mitad del siglo la documentación no es homogénea ni completa. La caótica información es el reflejo más inmediato de la inestabilidad del gobierno municipal, especialmente en materia de regidores. Así, si hasta la década de los cincuenta y sesenta el número de vacantes es mayor ello no se debe tanto al fallecimiento de los titulares, como a sus ausencias injustificadas o al rechazo por parte de los agraciados del nombramiento de regidor. Esto último se daba, explícita o implícitamente, no sacando el correspondiente título acreditativo. El «desgobierno» a que conducía semejante actitud originó sucesivos informes del Ayuntamiento o de la Audiencia (en 1721, 1729, 1732, 1738, 1741, 1744...) sobre el número de regidores que realmente servían sus oficios, plazas vacantes, individuos aptos para ocuparlas, $\mathrm{y}$, lo más importante, sobre las causas o razones que provocaban el relativo desinterés por estos empleos ${ }^{(57)}$.

Sin embargo, a partir de los sesenta el funcionamiento del Ayuntamiento es más regular y estable. La misma documentación lo pone de manifiesto. Las vacantes se producen por muerte de sus titulares, quedando sujetas a la periodicidad imprevisible que el carácter vitalicio de las regidurías les imprime. Esta estabilidad tiene su correlato en un mayor número de pretendientes por plaza, lo que lógicamente hace disminuir las posibilidades de ser elegido e induce a intentarlo nuevamente. De los 173 que sólo optaron una vez, obtuvieron plaza 29; entre quienes lo hicieron dos veces, 14 ; y 4 de los que se presentaron en tres ocasiones. Los que pretendieron a cuatro vacantes nunca fueron elegidos, pero sí que lo logró el que tenazmente aspiró en nueve ocasiones.

Este último hecho pone de manifiesto que el haber sido rechazado en varios intentos no impedía llegar a ser regidor. Aún cuando alguno de los primeros informes sobre el pretendiente en cuestión hubiera sido negativo, éste podría llegar a obtener la plaza siempre y cuando las razones por las que se le denegaba ya no existieran. Por ejemplo, el no haber acreditado suficientemente su «clase», es decir, su calidad de ciudadano o de hidalgo, o el poseer una renta considerada como corta. No obstante, el rechazo no siempre venía dado por la falta de méritos: aún poseyendo todos los requisitos, un pretendiente podía ser desestimado una y otra vez no llegando nunca a ser regidor. La inclinación más o menos partidaria de la Audiencia o del Ayuntamiento y la «natural» competencia y eliminación que el crecido número de aspirantes comportaba, explican, entre otras cosas, que se dieran casos como el citado más arriba. Veamos a continuación cuáles eran las condiciones que debía presentar un pretendiente.

\section{2.-Méritos alegados y requisitos exigidos}

Como anticipábamos, la fórmula a través de la cual un individuo ponía de manifiesto su deseo de llegar a ser regidor era la elaboración de un memorial. Enviado a la Cámara de Castilla por el interesado, se devolvía nuevamente a la ciudad, concretamente a la Audiencia, para que ésta, y posteriormente el Ayuntamiento, acredicasen si era cierto o no lo declarado por el pretendiente e infor- 
masen sobre el mismo. No siempre el memorial permite conocer a fondo la identidad del que lo suscribe, aunque en bastantes casos aporta toda una serie de datos sobre su origen y extracción social, profesión, si es que la tiene, renta que disfruta e, incluso, los motivos que le inducen a aspirar a la plaza.

Esta fuente documental nos ha permitido comprobar que, hasta bien avanzada la década de los treinta, uno de los méritos preferentes que habitualmente se muestran en los memoriales es el de la fidelidad y lealtad a Felipe V durante la Guerra de Sucesión. El argumento suele igualmente ir acompañado de referencias a su temporal exilio en Castilla - mientras el conflicto no se saldó- y a la pérdida de bienes, dinero y haciendas que el destierro ocasionó. Asimismo, es frecuente la mención explícita y alusión a su pasado propio o al de sus familiares como antiguos insaculados durante el gobierno foral de la ciudad. En consecuencia, demandaban que, como recompensa a los servicios prestados a la Corona, se les concediese una plaza de regidor. Continuidad en una trayectoria «burocráticaadministrativa» familiar y adscripción personal y expresa al nuevo proyecto político borbónico, se amalgamaban sin aparente contradicción en el sentir de los interesados. En conjunto, pues, los memoriales de esta primera etapa reflejan cumplidamente el espíritu de postguerra que el conflicto suscitó entre los triunfadores: Valencia es plaza conquistada, y su gobierno local forma parte del botín resultante, o al menos así lo pretenden los tempranos borbónicos de la ciudad. La lógica que proporciona sentido a los memoriales de este período parece invertir el dicho de Clausewitz: en el fondo, consideran que la política - en este caso, la política local - no es sino la continuidad de la guerra por otros medios. Lealtad y servicios prestados son el argumento. Sin embargo, conforme avanza la centuria y la rutinización política se asienta, este mérito deja de ser utilizado por los aspirantes a una plaza de regidor.

Sobre lo dicho quisiéramos destacar algunos ejemplos. Así, en 1721, José Raimundo Pardo expresa sus deseos de ocupar una regiduría en los términos siguientes:

«Dn. Joseph Raymundo Pardo, vecino de la Ciudad de Valencia (...) Dice que hallándose en la referida Ciudad, desde que felizmente la restauraron las Reales Armas de su instruso Govierno al suave yugo y dominio de V. M., se mantiene el suplicante en ella, sirviendo y asistiendo con la honra y crédito que es notorio, á quanto del Servicio de V. M. le han encomendado los Gefes y Superiores (...), con el maior desinterés, desapropio de utilidad, ni otro alguno emolumento (...); y respecto de ser asimismo notorio la fidelidad, zelo, y lealtad del Suplicante en todos tiempos a V. M. sin que hasta ahora se le aya remunerado en cosa alguna, y de desear ostentarlo y continuarlo en empleo, en que manifieste el Suplicante su propensión a la práctica del maior servicio de V. M.: Por lo que á V. M. rendidamente suplica sea de su Real agrado remunerar al Suplicante confiriéndole el empleo de Rexidor de la misma ciudad de Valencia... ${ }^{(58)}$. 
Lealtad y servicios prestados serán, tal y como hemos dicho, dos argumentos muy utilizados en las primeras décadas de la centuria. En el caso de Pardo, los trabajos que dice haber desempeñado son: la administración de la Renta del Tabaco en el partido de Morvedre y el descubrimiento y puesta en funcionamiento de unas «minas de alcohol» en dicho partido; todo ello "en nombre y para en derecho de la Real Hacienda» ${ }^{(59)}$.

Semejantes méritos fueron esgrimidos por Juan Crisóstomo Granell en 1724, para que se le concediera una plaza vacante de la clase de ciudadanos. Pero a ellos añadía otra razón bastante peculiar: el salario que percibía como fiscal de las Rentas Reales de la ciudad de Valencia le resultaba insuficiente para hacer frente a los «empeños» de su casa, derivados, en parte, del corto tiempo en que su hermano, el Dr. Pedro Granell, ocupó la Mitra de Barbastro, cuyos gastos «aún oy le oprimen) ${ }^{(60)}$.

Según se deja ver en el memorial, el cargo de fiscal que ocupaba se le concedió en 1712 como pago, también, a su fidelidad a la nueva Monarquía:

«...en atensión a lo que gustosamente padezió en los Saqueos destierros y furiosas persecuziones, con que fue ultrajado el Suplicante, Su casa, familia y Parientes, por los Sediziosos en las turbaciones pasadas del Reyno de Valencia por ser el blanco de su perfidia la insensible lealtad del suplicante á la Justísima y siempre Amada obediencia de V. M...» ${ }^{(6)}$

Juan Crisóstomo Granell obtuvo el título de regidor en 1728, y ejerció hasta 1745, fecha en la que se concede a su hijo, José Granell, la plaza que aquel ocupaba, aunque no por juro de heredad, como pedía ${ }^{(62)}$. Resulta muy significativo ver cómo en el memorial enviado por este último solicitando la plaza del padre repite los mismos argumentos utilizados en su día por el primero: saqueo de su casa, deudas contraidas, e incluso lo insuficiente que le resulta el sueldo de 246 libras que disfruta como fiel contador de la alhóndiga de trigo de Valencia desde 1731, y que sirve mediante teniente, ya que él se encuentra en Madrid como caballerizo de Campo sin salario alguno por tal concepto. Por ello, añade, para poder «dar algún consuelo a sus viejos Padres, y poder mantener su dilatada familia con la presisa desensia...» desea que se le conceda por juro de heredad, tanto la plaza de regidor de su padre, como el fielato de la alhóndiga ${ }^{(63)}$.

Mas que por promoción y ascenso social, da la impresión que llegar a ser regidor podía constituir, desde el punto de vista económico, una inversión rentable. Sin embargo, si se comparan los 3.690 reales anuales que percibía Granell por el fielato, con los 450 reales, también anuales, que en esas fechas ganaba un regidor, no lo era tanto. La explicación del interés que podría suscitar, a este nivel, ocupar una regiduría excede de la remuneración legalmente estipulada: hasta 1767 , en que los 450 reales se incrementaron a 750 , los regidores disponían de otros emolumentos secundarios derivados del ejercicio de ciertas comisiones relacionadas con los abastos de la ciudad, concretamente con el trigo, el vino y la carne, y que superaban lo recibido en concepto de salario ${ }^{(64)}$. 
La suficiencia económica será, precisamente, otro de los requisitos exigidos a los pretendientes. Contrarrestar el escaso nivel del sueldo y evitar posibles malversaciones de fondos en el Ayuntamiento era la razón esgrimida. Pero, en realidad, lo que conscientemente se pretendía era limitar el gobierno de la ciudad a unos pocos, a los mejor situados social y económicamente, pero siempre conforme a los valores aún vigentes de la sociedad estamental.

En conjunto, los criterios a partir de los cuales se debía valorar o juzgar los méritos alegados por los pretendientes no empiezan a estar claros hasta los años sesenta de la centuria. Precisamente cuando es el propio Ayuntamiento el que trata de imponer dichos criterios. Fielmente inspirados en los que regían durante el pasado gobierno foral, los requisitos que tenía que acreditar toda persona que optase a una plaza de regidor eran los siguientes ${ }^{(65)}$ :

a) Ser descendiente de familia de ciudadanos de inmemorial o insaculados, o bien gozar del privilegio de hidalguía, según se tratara de una Regiduría de la clase de ciudadanos o de nobles.

b) Poseer una renta anual mínima, que si bien nunca estuvo estipulada de forma fija, hasta $\mathbf{1 7 6 5} \mathrm{se}$ cifró en 400 libras. A lo largo de la centuria, y en sucesivas ocasiones, se trató de obtener la autorización de la Cámara para que ese mínimo se aumentase. Así, en 1765 se dice que ha de superar las 400 libras; en 1777 que debe alcanzar las 800; y en 1789 que no puede bajar de las 100 libras. Siempre sin incluir en dicha renta los bienes dotales. Aunque no puede precisarse si esas variaciones llegaron a reconocerse legalmente, en la práctica se actuó conforme a ellas (66).

c) Ser natural y vecino de Valencia o su «Reyno», con preferencia ante cualquier forastero con iguales circunstancias y méritos.

d) No ejercer otro oficio inferior al de regidor, y en su caso que el horario no fuera incompatible con el de este último. Pero, sobre todo, que ni el pretendiente ni sus padres realizaran, o hubieran realizado alguno de los oficios considerados como mecánicos y viles.

En este punto la Real Cédula de 18 de marzo de 1783 iba a permitir el acceso al cargo de regidor a individuos procedentes de la menestralía y del comercio ${ }^{(67)}$. Sin embargo, sus efectos en la práctica no fueron espectaculares, al menos en Valencia.

e) Por último, no tener lazos de parentesco, hasta el cuarto grado, con otros miembros del Ayuntamiento, si bien éste fue un requisito que no siempre se cumplió estrictamente. La referencia legal que suele tomarse es la Real Cédula de 15 de noviembre de 1767 , en uno de cuyos apartados se dice:

«Igualmente declaro por punto general, que el enlace de parentescos, que se prohibe entre los Diputados y Síndicos Personeros y los Oficiales de Justicia, debe entenderse con los Alcaldes y demás Capitulares que entran») ${ }^{(68)}$

De todos estos requisitos, los más utilizados por el Ayuntamiento y por la Audiencia fueron los dos primeros: clase y renta. El no ejercer oficio mecánico, tanto por parte del pretendiente, como del padre o familiares del mismo, fue ob- 
jeto, igualmente, de especial atención, aunque no fueron abundantes los casos en que se dió esta circunstancia.

A partir de los memoriales de los pretendientes hemos podido conocer la renta anual que poseían, pero sólo, evidentemente, de aquellos que la declaran: 129 individuos entre 1765 y 1804 . Para la primera mitad del siglo las propias irregularidades de la documentación hacen imposible, por el momento, precisar este dato de tanta importancia. Por ello, en el cuadro que presentamos a continuación sólo están considerados esos 129 sujetos que pretenden entre 1765 y 1804 . A su vez, hemos dividido las variables tiempo y renta en cuatro y cinco grupos respectivamente, con el fin de ver qué porcentaje de pretendientes corresponde a cada uno de ellos y qué evolución se opera según el tipo de renta.

\section{PORCENTAJE DE PRETENDIENTES SEGÚN EL TIPO DE RENTA} (En libras)

\begin{tabular}{|l|c|c|c|r|r|}
\hline \multicolumn{1}{|c|}{ PERÍODOS } & $\mathbf{4 0 0}$ & $\mathbf{4 0 0 / 3 0 0 0}$ & $\mathbf{1 0 0 1 / 1 5 0 0}$ & $\mathbf{1 5 0 1 / 2 0 0 0}$ & $+\mathbf{2 0 0 0}$ \\
\hline $1765 / 74$ & 13,33 & 46,66 & 26,66 & 6,66 & 6,66 \\
$1775 / 84$ & 6,81 & 38,63 & 22,72 & 13,63 & 18,18 \\
$1785 / 94$ & 6,21 & 36,73 & 32,65 & 8,16 & 16,32 \\
$1795 / 1804$ & - & 47,65 & 14,28 & 4,76 & 33,33 \\
\hline
\end{tabular}

Elaboración propia a partir de las fuentes citadas en la nota (52).

Lo primero que puede advertirse es el considerable porcentaje de pretendientes con una renta media-baja entre las 400 y las 1.000 libras, en los cuatro grupos de años. Ello significa que, desde el punto de vista económico, siempre hubo aspirantes potencialmente aptos para ocupar una plaza de regidor. Como se recordará, el mínimo considerado como necesario a la altura de 1789 era de 1.000 libras. Pero no sólo esto, sino que ese mínimo se superaba incluso cuando lo exigido era inferior, destacando el $26,66 \%$ de pretendientes que entre $1765-74$ poseen una renta que oscila entre las 1.001 y las 1.500 libras. Es este tercer grupo el que se sitúa, a lo largo del período 1765-94, en segundo lugar después de los comprendidos entre las 400 y las 1.000 libras, sólo superado en $1795-1804$ por ese 33,33\% con más de 2.000 libras. Por el contrario, mucha menos importancia porcentual presenta el grupo situado entre las 1.501 y las 2.000 libras, el cual, salvo el ligero aumento de $1775-84$, ofrece cifras muy por debajo del resto de grupos $(6,66 ; 8,16$; $4,76)$, en claro contraste con ellos.

Igualmente significativo resulta el bajo número de quienes declaran una renta inferior a las 400 libras. Si entre 1765-74 tienen cierta presencia, con ese 13,33\% por encima incluso de los grupos de 1.501-2.000 y de más de 2.000 libras, entre 1775 y 1804 va decreciendo hasta llegar a desaparecer en el último período.

Por tanto, puede afirmarse que el módulo económico de los pretendientes siempre alcanzó, e incluso superó, el establecido por el Ayuntamiento, aunque 
también siempre fueron mayoritarios los compredidos entre las 400 y las 1.000 libras, seguidos por los grupos de 1.001-1.500 y más de 2.000 libras. La renta mediabaja y media con tendencia a alta caracteriza a los aspirantes a regidor, si bien esto debe relativizarse dado el elevado número de quienes no la declaran y que, en consecuencia, no pueden incluirse en estos porcentajes. Posiblemente esa renta se hubiera visto afectada en sentido ascendente, si tenemos en cuenta que algunos de los títulos nobiliarios, precisamente por serlo, obvian este dato en sus memoriales, como, por ejemplo, el marqués de Sotelo, el conde de Castellar, el marqués de Valera o el barón de Tamarit, y se conforman con alegar que poseían «pingúes rentas».

De forma global, para el conjunto del período señalado, el porcentaje de pretendientes para cada grupo de renta es el siguiente:

\begin{tabular}{|c|r|}
\hline GRUPOS DE RENTA (en libras) & $1765 / 1804$ \\
\hline-400 & $6,20 \%$ \\
$400 / 1000$ & $40,31 \%$ \\
$1001 / 1500$ & $25,58 \%$ \\
$1501 / 2000$ & $9,30 \%$ \\
+2000 & $18,60 \%$ \\
\hline
\end{tabular}

Elaboración propia a partir de las fuentes citadas en la nota (52).

$\mathrm{Al}$ igual que con la renta, los memoriales nos han servido como fuente para poder aproximarnos a la estructura profesional de los pretendientes. Tampoco en este punto el resultado afecta a la totalidad de ellos, sino únicamente a quienes la declaran, destacando un $25,69 \%$ que no lo hace. El resto se distribuye del siguiente modo:

ESTRUCTURA PROFESIONAL DE LOS PRETENDIENTES

\begin{tabular}{|l|c|}
\hline \multicolumn{1}{|c|}{ PROFESIONES } & PORCENTAJE \\
\hline Doctores en derecho & 21,98 \\
Militares & 15,78 \\
Hacendados & 24,45 \\
Comerciantes & 2,47 \\
Empleados & 8,04 \\
Escribanos & 0,61 \\
Menestrales & 0,30 \\
\hline
\end{tabular}

Elaboración propia a partir de las fuentes citadas en la nota (52). 
Los porcentajes son por sí solos significativos. Destaca la abrumadora presencia de las tres primeras categorías: doctores en derecho, militares y hacendados. Juntas suponen en $62,2 \%$ de los pretendientes. Esto cobra mayor importancia cuando confluyen en un mismo sujeto dos de ellas, por ejemplo hacendado y doctor. Sin embargo, el porcentaje del primer grupo no se corresponde luego con una mayor presencia de letrados entre los regidores. La renta y, sobre todo, la clase (ciudadano o caballero) serían determinantes; el crédito y fama de un abogado no eran suficientes si ello no venía acompañado, ante todo, por su condición de clase.

El otro aspecto a resaltar es el escaso porcentaje de comerciantes y menestrales; estos últimos prácticamente inexistentes, pues como tal sólo se presenta uno en 1800. Ello se corresponde, a su vez, con una présencia real en el Ayuntamiento por parte de los comerciantes casi simbólica: los pocos que consiguieron una regiduría antes fueron declarados hidalgos, y uno la adquirió mediante compra ${ }^{(69)}$.

La categoría de empleados corresponde aquí a aquellos que trabajan en alguna de las nuevas instituciones de la Monarquía. Lo que podríamos denominar oficiales reales, entre los cuales, a su vez, no es extraño que también se encontrase algún hacendado.

La estructura profesional de los pretendientes aparece, pues, condicionada por las mismas limitaciones sociales y económicas que la división de regidores en dos clases imponía. La Real Cédula de 18 de marzo de 1783 pudo haber ampliado el espectro sociológico de los aspirantes a una plaza en el Ayuntamiento de Valencia. Sin embargo, sus efectos apenas si se notaron. La mencionada división y los criterios de selección no sólo continuaron vigentes en la práctica, sino que incluso hubo un reforzamiento en sentido aristocrático de la corporación municipal. La tendencia al ennoblecimiento por parte de la clase mercantil no sería más que uno de los factores que contribuirían a ello, pero no de los principales, habida cuenta de su reducida presencia entre los regidores.

Hasta aquí nos hemos venido refiriendo al número de pretendientes, a su renta y a su estructura profesional, sin reparar en una cuestión que reviste, a nuestro modo de ver, suma importancia; la actitud de la nobleza titulada ante las posibilidades que la nueva composición del Ayuntamiento le ofrecía después de 1707, máxime cuando $2 / 3$ de las plazas estaban destinadas a miembros de su estamento.

\section{LA NOBLEZA TITULADA ANTE LAS PLAZAS DE REGIDOR}

Con frecuencia, nos hemos venido refiriendo a un proceso de ennoblecimiento del Ayuntamiento valenciano, que se remontaba a la época foral y que adquiría nuevas fuerzas tras la implantación de la legislación castellana. De inmediato, y habida cuenta de la existencia de un cuerpo nobiliario en absoluto homogéneo, nos preguntamos en qué medida quienes pertenecían al mismo detentando un título se interesaron por el oficio de regidor. Una vez más, los memoriales ofrecen la posibilidad de llegar a conocer cuántos de estos pretendieron y cuándo. 
Prescindiendo del nombramiento masivo de regidores efectuado por el monarca en $1707^{(70)}$, entre 1714 y 1800 desean llegar a alcanzar una regiduría 16 individuos con título nobiliario. Ello supone el $6,08 \%$ con respecto al total de 263 pretendientes calculados para el mismo período. La cifra es en sí misma baja. Ahora bien, si en lugar de contabilizar personas contabilizamos títulos, tenemos que éstos se limitan a 12, viéndose afectado, por tanto, el porcentaje, que se reduce a un $4,56 \%$. En un caso u otro, insistimos en que su número es ostensiblemente

\section{PRETENDIENTES CON TÍTULO NOBILIARIO}

\begin{tabular}{|c|c|c|}
\hline PRETENDIENTES & AÑo & REGIDOR \\
\hline 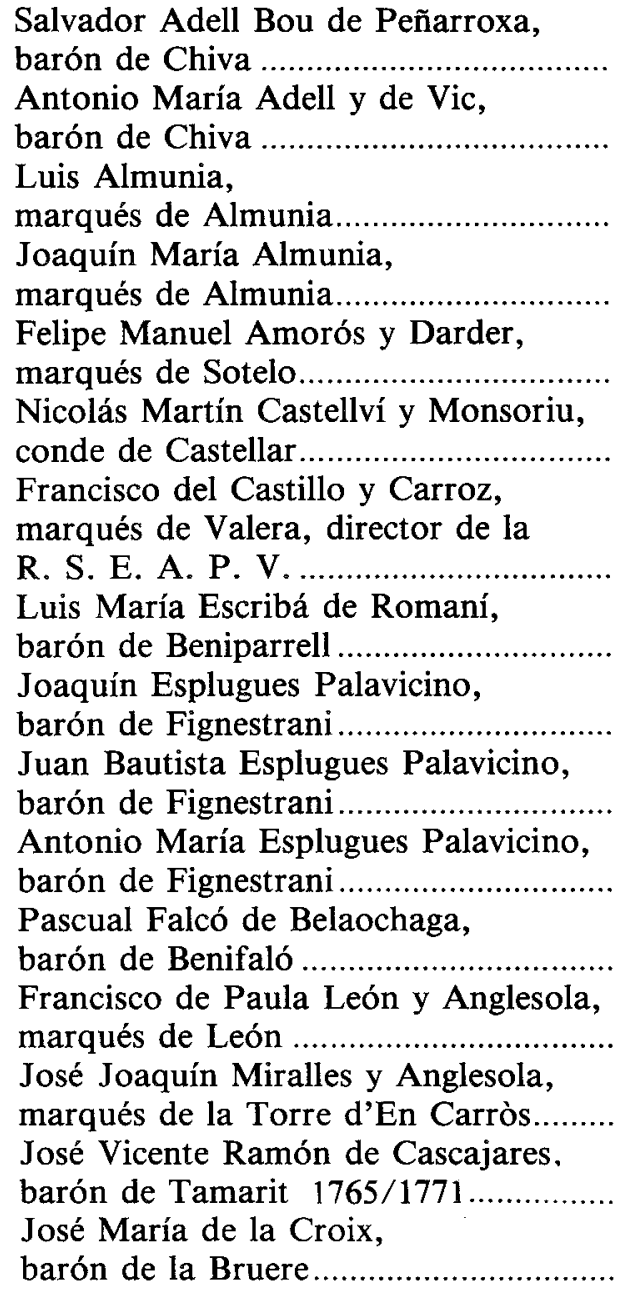 & $\begin{array}{c}1722 \\
1793 \\
1732 / 1737 \\
1784 / 1786 \\
1793 / 1798 / 1799 \\
1729 \\
1793 \\
1793 / 1798 / 1799 \\
1739 \\
1782 \\
1793 / 1799 \\
1798 / 1799 \\
1786 \\
1786 \\
1771 / 1805 \\
1790\end{array}$ & $\begin{array}{r}- \\
- \\
1800 / \\
-\end{array}$ \\
\hline
\end{tabular}

Elaboración propia a partir de las fuentes citadas en la nota (52). 
bajo si lo comparamos con los doctores en derecho, o incluso con los empleados, superando tan sólo a comerciantes, menestrales y escribanos ${ }^{(7)}$.

Desde el punto de vista cronológico, las pretensiones se dan en dos períodos amplios y concretos, cuatro entre 1722 y 1748 , y doce entre 1765 y 1799 , tal y como puede verse en el cuadro.

Si prescindimos del intento llevado a cabo por el barón de Tamarit en 1765 - puesto que no se le concedió en esa ocasión la plaza de regidor-, vemos cómo desde 1740 hasta 1782 no pretende ningún título nobiliario, y los que lo hacen durante la segunda mitad de la centuria se concentran en las dos últimas décadas. Ahora bien, no hubo igual correspondencia entre el número de aspirantes y el de concesiones en los dos períodos señalados (1722-1748 y 1765-1799). Y esto es así porque, mientras que de los cuatro pretendientes del primero obtienen plaza tres, en el segundo sólo lo conseguirán cuatro. De lo que se infiere que, si bien el interés de este grupo de la nobleza parece mayor en las postrimerías del siglo, no por ello tuvo más presencia real en el gobierno de la ciudad.

Sin embargo, el número de títulos nobiliarios que ocupó una plaza de regidor en el Ayuntamiento de Valencia quedaría desvirtuado y falseado si operáramos únicamente con los datos que nos proporcionan los memoriales. Deberemos tener en cuenta, además, los nombramientos realizados directamente por el monarca en 1707 y $1715^{(72)}$, y las regidurías obtenidas mediante compra o heredadas de quienes las poseían a perpetuidad ${ }^{(73)}$. Considerando ambos hechos, el total de títulos y de individuos que los ostentaban, que formaron parte del gobierno de la ciudad, fue muy superior. Hemos contabilizado 29 casas nobiliarias para una suma de 34 regidores, repartidos en su ejercicio de forma desigual a lo largo de la centuria. Entre 1707 y 1739-1748 obtuvieron plaza de regidor 22 de esas 29 casas nobiliarias, es decir el $75,86 \%$. Las siete restantes entre 1765 y 1799 . Si, por el contrario, atendemos al reparto de plazas, tenemos que en la primera mitad se ocuparon 23 , y en la segunda 11 .

\section{REPARTO DE REGIDURÍAS EN EL AYUNTAMIENTO DE VALENCIA POR CASAS NOBILIARIAS}

\begin{tabular}{|c|c|c|c|c|}
\hline PERIODO & CASAS NOBILIARIAS & PORCENTAJE & REGIDORES & PORCENTAJE \\
\hline $1701 / 1748$ & 22 & 75,86 & 23 & 67,64 \\
$1765 / 1799$ & 7 & 24,13 & 11 & 32,35 \\
\hline
\end{tabular}

Elaborado a partir de las fuentes citadas en las notas (52) y (73).

Un hecho resulta, en principio, evidente: la presencia de títulos nobiliarios en el Ayuntamiento de Valencia se reduce de forma ostensible durante la segunda mitad del siglo XVIII. Ahora bien, el desigual reparto es susceptible de matizaciones importantes. 
De los 23 regidores que hemos enmarcado en el primer peíodo, 15 fueron nombrados directamente por el monarca en 1707. Otros 5 fueron elegidos de igual modo en 1715-16, con motivo de la remodelación de que fue objeto el gobierno de la ciudad. Y sólo 3 obtuvieron plaza a través del mecanismo de la pretensión, entre 1722 y 1748 , como ya vimos. Por tanto, el momento en que hubo un mayor porcentaje de regidores con título nobiliario se sitúa entre 1707 y 1715 , en que supuso el $62,5 \%$ de las regidurías de la clase de caballeros, y el $46,87 \%$ del total de caballeros y ciudadanos. Es decir, aproximadamente la mitad del cuerpo municipal. Nunca más volvería a darse una situación de este tipo, si bien en 1715-16 aún se mantuvieron ciertas casas nobiliarias: tres presentes ya en 1707 y cinco de nuevo nombramiento. Un total, pues, de ocho títulos frente a los quince de 1707.

Por lo que respecta a los 11 que obtuvieron la plaza entre 1765 y 1799 hemos de precisar que siete lo eran por juro de heredad (seis por directa sucesión y uno por compra) y comprendían cuatro de los siete títulos. Los otros cuatro regidores, como también vimos, accedieron tras haber aspirado a ella. Esto último es importante, puesto que las regidurías que tenían un carácter perpetuo, y no vitalicio, garantizaban la continuidad de la casa nobiliaria en el gobierno de la ciudad, a no ser, como ocurrió en algún caso, que se enajenaran entre particulares. Y también lo es el hecho de que dos de los propietarios de regidurías perpetuas obtuvieran el título nobiliario siendo ya regidores. Por tanto, si tenemos en cuenta que la mayor parte de ellas fueron dotadas en 1739 a individuos que, en ese momento, carecían de título nobiliario, podemos concluir que, de esas 11 plazas de regidor, tan sólo las cuatro concedidas en las dos últimas décadas del siglo se dieron a títulos en cuanto tales.

En conjunto, y sin entrar en el análisis de qué nobles ocuparon un sillón consistorial, lo cierto es que la nobleza valenciana, tras una presencia masiva en las primeras décadas, parece abstenerse de participar directamente en lo que constituía uno de los principales órganos de gestión política a escala local. Tras la Nueva Planta tuvo ocasión para ello, pero sin solución de continuidad. Las razones de ese absentismo no deben buscarse sólo en los intereses de esa nobleza posiblemente más preocupada por rehacer sus haciendas y unir patrimonios-, sino también, y sobre todo, en las características del nuevo gobierno municipal. Un gobierno supeditado a la autoridad de los intendentes-corregidores, encargados de fiscalizar y centralizar la vida local en todas sus facetas ${ }^{(74)}$. Un gobierno en el que el margen de maniobra de los regidores era escaso, especialmente en cuestiones tan importantes como las rentas de la ciudad. Un gobierno, en suma, instaurado por la Monarquía y en función de los intereses de la misma. El absolutismo monárquico sólo pudo ser posible llevando a cabo una centralización administrativa y una unificación legislativa que pasaban, necesariamente, por la reestructuración de los gobiernos municipales, como áreas de poder que eran. Las vías de acceso al mismo fueron objeto, igualmente, de modificaciones, tanto en lo que se refiere al sistema de elección, como a la naturaleza de los individuos susceptibles de ser elegidos. El absentismo de la antigua nobleza facilitó el que 
una nueva oligarquía, y con ella una nueva nobleza, ocupara, predominantemente, los cargos de regidor ${ }^{(75)}$.

\section{NOTAS}

(1) Sobre la abolición de los fueros valencianos y sus consecuencias más inmediatas Cf.: PÉREZ PUCHAL, P.: «La abolición de los fueros de Valencia y la Nueva Planta», Saitabi, XII, Valencia, 1962, pp. 179-198; PESET REIG, M.: «Notas sobre la abolición de los fueros de Valencia», Anuario de historia del derecho español, XLII, Madrid, 1972, pp. 657-715; Id.: «La creación de la Chancillería de Valencia y su reducción a Audiencia en los años de la Nueva Planta», en Estudios de Historia de Valencia, Valencia, Universidad de Valencia, 1978, pp. 309-334.

Para el caso de Alicante, contamos con la obra de PRADELLS NADAL, J.: Del foralismo al centralismo. Alicante, 1700-1725. Alicante, Universidad de Alicante-Caja de Ahorros Provincial de Alicante, 1984.

Para el conflicto bélico en Valencia, véase: PÉREZ APARICIC, C.: «La guerra de Successió: una revolució camperola", en Primer Congreso de Historia del País Valenciano. Valencia, 1976, vol. III, pp. 511-524. También de la misma autora, De l'alçament maulet al triomf botifler. Valencia, Eliseu Climent, ed., 1981.

(2) FERNÁNDEZ ALBALADEJO, P.: «La transición política y la instauración del Absolutismo», Zona Abierta, 30, 1984, p. 71.

(3) BELENGUER CEBRIÁ, E.: València en la crisi del segle XV, Barcelona, Edicions 62, 1976.

(4) Aunque refiriéndose a las Cortes valencianas, Sylvia Romeu ha incidido en esta cuestión: «...determinada historiografia (...) d'exaltació nacionalista i acrítica (...) tracta de destacar uns pretesos trets democràtics que haurien conformat la institució enferma oposició a un poder reial desmesurat y arbitrari (...). Insistir sobre el pretés caràcter democràtic d'aquestes assemblees és ignorar el paper que les diferents classes socials i la mateixa monarquia exercien» (ROMEU ALFARO, S.: Les Corts Valencianes, Valencia, Eliseu Climent ed., 1985, p. 14).

(5) En 1903, uno de sus representantes, Gumersindo de Azcárate, se refería a la «vida tan hermosa de los municipios en la Edad Media», que «murió en gran parte a manos de la Monarquía (...) para reconcentrar el poder» (AZCÁRATE, G. de, «Discurso pronunciado en el debate del proyecto de Ley de Régimen Local de Maura", en Id.: Municipalismo y regionalismo, Madrid, Instituto de estudios de Administración Local, 1979, pp. 218-219). Por su parte, el cronista valenciano Vicente Boix, al preguntarse qué quedaba en pleno siglo XIX del régimen foral valenciano, respondía: «Todo ha ido desapareciendo desde que Felipe $\mathrm{V}$ abolió despóticamente la libertad de Valencia. La obra del gran Rey aragonés Jaime I fue destruida por el Rey francés Felipe de Anjou» (BOIX, V.: Apuntes históricos sobre los Fueros del Antiguo Reino de Valencia, Valencia, 1855, VII).

(6) CLAVERO, B.: «Para un concepto de revolución burguesa». Sistema, 13, 1976, p. 44.

(7) GARCÍA FERNÁNDEZ, J.: El origen del municipio constitucional: autonomía y centralización en Francia y en España, Madrid, Instituto de estudios de Administración local, 1983, pp. 22-23.

(8) Los probi homines o ciudadanos honrados, según señala Villalonga, eran los únicos que tenían acceso al cargo de jurado, desde que éste quedó instituido en 1245. Este mismo autor, al comentar el privilegio de Pedro I, de 1278 - por el que se trató, sin resultado, de ampliar numérica y cualitativamente esta magistratura-, los identifica socialmente como «burguesía industrial y mercantil» (VILLALONGA, I.: Los Jurados y el Consejo, Valencia, 1916, pp. 6 y 10). Madramany, en pleno siglo XVIII, nos dice que el término de ciudadano definía en la antigua Corona de Aragón a «las personas que no exercían oficio alguno vil ni mecánico, sino que se mantenían de sus rentas sin 
necesidad del trabajo corporal», y que a esas personas se les aplicaba el calificativo de honrados para distinguirlos de los plebeyos (MADRAMANY Y CALATAYUD, M.: Tratado de la Nobleza de la Corona de Aragón, especialmente del Reyno de Valencia, comparada con la de Castilla, para ilustración de la Rl. Cédula del Señor Don Luis I de 14 de agosto de 1724, Valencia, Josef y Tomás de Orga, 1788, p. 406).

\section{(9) MADRAMANY Y CALATAYUD, M.: Tratado de la Nobleza..., p. 314.}

(10) Cf. TORRAS I RIBE, J. M.: «El municipi catalá durant els segles XVI y XVII» en AA. VV., El govern de les ciutats catalanes, Barcelona, Institut Municipal d'Història-La Magrana, 1985, passim.

Aunque el proceso de aristocratización valenciano es similar al catalán (dejando al margen fechas concretas en las que la nobleza - con o sin título- accede a los gobiernos municipales), la ausencia, en nuestro caso, de comerciantes y menestrales entre los jurados nos induce a pensar que dicho proceso fue más intenso en Valencia que en Cataluña; incluso que en Mallorca o en algunas otras ciudades del País Valenciano. En Barcelona, a mediados del siglo XVII, los seis consellers (jurats en Valencia) se distribuían del siguiente modo las plazas: tres correspondían a caballeros, ciudadanos honrados o doctores en derecho y medicina, el cuarto a un comerciante, el quinto a un artista o menestral y el sexto, nombrado en 1641, también a un menestral (TORRAS I RIBE, J. M.: Els municipis catalans de 'Antic Règim (1453-1808), Barcelona, Curial, 1983, pp. 63 y 64). Mallorca y Zaragoza también presentan sus peculiaridades. En la primera, de los seis jurados, uno era caballero, dos ciudadanos, dos mercaderes y uno artista y/o menestral (citado por TORRAS I RIBE, J. M.: Els municipis catalans..., pp. 63-64). En Zaragoza, por el contrario, los comerciantes serían excluidos de los cargos municipales desde 1561 REDONDO VEINTEMILLAS, C., «Cargos municipales y participación artesana en el Consejo Zaragozano, 1584-1706», Estudios del Departamento de Historia Moderna, Zaragoza, Facultad de Filosofía y Letras, 1976, pp. 159-190, citado por CASEY, J.: El Reino de Valencia en el siglo XVII, Madrid, Siglo XXI, 1983, pp. 179-180). El caso de Castelló de la Plana es especialmente singular, sobre todo si tenemos en cuenta su proximidad a Valencia: gozaba del privilegio de insaculación desde 1446, formando parte de sus listas nobles, ciudadanos, gremio de artistas - notarios, boticarios y cirujanos - y «campesinos» distribuyéndose las cuatro magistraturas a razón de una por cada grupo, excepto los últimos, que podían llegar a tener dos si la nobleza no participaba. Sin embargo, los gremios de artesanos nunca consiguieron llegar̀ a formar parte de las listas (CASEY, J.: El Reino de Valencia..., p. 180).

La presencia de los artesanos en el gobierno de Barcelona ha sido puesta de relieve por Amelang, comparando a esta ciudad con la tendencia seguida por otras ciudades, especialmente las italianas. Cf., AMELANG, J.: «L'oligarquia ciutadana a la Barcelona moderna: una aproximació comparativa», Recerques, 13, 1983, pp. 7-25. Del mismo autor puede consultarse su reciente publicación, $L a$ formación de una clase dirigente: Barcelona 1490-1714, Barcelona, Ariel, 1986.

En Valencia, las ocasiones que tuvo la menestralía de acceder al cargo de jurado, nunca se saldaron positivamente. Ni cuando ello fue obra de un monarca, en 1278 , ni durante las Germanías. Sobre este movimiento Cf., GARCÍA CÁRCEL, R.: Las Germanías de Valencia, Barcelona, Península, 1975.

(11) Belenguer Cebrià, siguiendo las etapas propuestas por Villalonga, en op. cit., para el municipio foral valenciano, situa el inicio de la decadencia o pérdida de su autonomía en el siglo XV, con el cambio de dinastía (BELENGUER CEBRIÁ, E.: València en la crisi..., pp. 33-43). Ahora bien, sin rechazar esta tesis, Sylvia Romeu precisa que los cambios o transformaciones son anteriores, destacando la entrada de los caballeros y generosos en 1321, como factor de aristocratización (ROMEU ALFARO, S.: Les Corts..., p. 33).

(12) BELENGUER CEBRIÁ, E.: València en la crisi..., pp. 25-39. Sobre el racional, este autor señala: «...és l'home del rei,gairebé a la manera del Corregidor castellà —creat, amb Isabel, a Castella. Ell és qui confecciona la "Ceda" i la tramet al rei, qui suggereix uns noms per als càrrecs municipals i qui controla, en conseqüencia, tota la vida ciutadana...», convirtiéndose en «un polític reial que exercia funcions gairebé dictatorials» (p. 40).

(13) Tesis mantenida por el profesor Reglà, para quien la insaculación fue una forma de manifestarse la progresiva intervención real en los municipios. Cf., REGLA, J.: Introducción a la historia de la Corona de Aragón, Palma de Mallorca, Moll, 1969, p. 79.

(14) BELENGUER CEBRIÁ, E.: València en la crisi..., pp. 96-97.

(15) TORRAS I RIBÉ, J. M.: «El municipi català...», p. 96.

(16) Respecto a esta importante cuestión, Lluís Guia señala que «l'existència d'una sèrie de faccions entre l'oligarquia, els mètodes d'actuació de la qual conectaven directament amb el bandoleris- 
me, coneixia al segle XVII un anormal pes específic en la vida política valenciana. La violència era utilitzada pels sectors dominants, uns contra els altres, en funció de consolidar llurs posicions de poder a les comunitats locals» (GUÍA MARÍN, Ll.: «Dissidència política i repressió social al País Valencià a mitjan segle XVII», Saitabi, XXXIV, 1984, p. 107).

Sobre el bandolerismo valenciano del Barroco, Cf., GARCÍA MARTÍNEZ, S.: Bandolers, corsaris $i$ moriscos, Valencia, Eliseu Climent, ed., 1980.

(17) CASEY, J.: «La crisi general del segle XVII a València, 1646-1648», Boletín de la Sociedad Castellonense de Cultura, XLVI, 1970, p. 100. En este mismo artículo, el autor estudia el comportamiento de las distintas facciones de la oligarquía en conexión con el problema del bandolerismo y de la situación financiera de la Monarquía.

(18) CASEY, J.: El Reino de Valencia..., p. 173.

(19) CASEY, J.: «La crisi general...», p. 100.

(20) Ibid., p. 104.

(21) Los privilegios de 1633 y 1648 pueden encontrarse en MADRAMANY Y CALATAYUD, M.: Tratado de la Nobleza..., apéndice documental, documentos núm. XIl y XIV.

(22) MADRAMANY Y CALATAYUD, M.: Tratado de la Nobleza..., documento núm. XIV.

(23) CASEY, J.: «La crisi general...», p. 127.

(24) MADRAMANY Y CALATAYUD, M.: Tratado de la Nobleza..., p. 87. Las peticiones de este sector del estamento nobiliario datan de 1626 y 1631 , habiendo llegado a entablar un pleito para poder acceder a los oficios municipales (p. 86 y documento núm. LXIV).

(25) En este sentido, Molas apunta: «Tot allò que a València va ser pressa a establir el sistema de govern de Castella sense veure ni tan sols si seria favorable per al mateix Estat, en el cas del Principat de Catalunya, dóna lloc a un periodo de reflexió (MOLAS RIBALTA, P.: «El municipi català sota el règim borbònic», en AA. VV., El govern de les ciutats catalanes, Barcelona, Institut Municipal d'Història-La Magrana, 1985, p. 104).

(26) Este aspecto ha sido tratado más ampliamente en mi tesis doctoral, Absolutismo y poder local. La reorganización de la oligarquía urbana en el Ayuntamiento de Valencia (1707-1800), Valencia, 1987, pp. 81-154.

(27) (A)rchivo (H)istórico (N)acional, Consejos, leg. 17.984.

(28) (A)rchivo (G)eneral de (S)imancas, Gracia y Justicia, leg. 800.

(29) MANCEBO, M. F.: «El primer Ayuntamiento borbónico de la ciudad de Valencia», en Estudios de Historia de Valencia, Valencia, Universidad de Valencia, 1978, pp. 293-297.

(30) La unión de Intendencias y Corregimientos en las capitales donde tuviera su residencia la primera se realizó en virtud de un Real Decreto de 4 de julio de 1718 (KAMEN, J.: «El establecimiento de los Intendentes en la Administración española», Hispania, 95, 1964, p. 376).

En la ciudad de Valencia, la unión de funciones en una misma persona se llevó a cabo en agosto de 1718, al ser nombrado intendente corregidor «de los Reinos de Valencia y Murcia, y de la ciudad de Valencia» Luis Antonio de Mergelina y Mora (AHN, Consejos, leg. 18.251).

(31) Por Real Cédula de 13 de noviembre de 1766 (Novísima Recopilación, Lib. VII, Tít. XI. Ley XXVI).

(32) La propuesta de separación de ambos cargos hecha por el Consejo, en 1766, fue aprobada por el monarca con la salvedad de que quienes en ese momento los ocuparan continuasen en ellos hasta que fuesen promovidos a otro empleo [AHN, Consejos, leg. 6.855 (27)]. Así, en Valencia, su titular en esas fechas, Andrés Gómez de la Vega, se mantuvo hasta 1770, en que fue ascendido a ministro del Consejo de Guerra, y sustituido como corregidor por Diego Navarro (AHN, Consejos, leg. 18.251). Sobre las ordenanzas y normativas dictadas a lo largo del siglo XVIII relativas a los intendentes y corregidores, Cf., GONZÁLEZ ALONSO, B.: El Corregidor castellano (1348-1808) Madrid, Instituto de Estudios Administrativos, 1970, especialmente pp. 245-279.

(33) Novisima Recopilación. Lib. VII. Tít. XI. Ley XXIV.

(34) Novísima Recopilación. Lib. VII. Tít. XI. Ley XXIX. Sobre la función de los alcaldes mayores, González Alonso afirma: «Importa, sobre todo, (...) destacar la doble condición de los alcaldes mayores, en ocasiones verdaderos órganos de la Administración en mayor medida que auxiliares 
de los corregidores, por más que éstos aparezcan siempre como superiores jerárquicos con funciones (...) fiscalizadoras en las demarcaciones que componen el Corregimiento", Cf., GONZÁLEZ ALONSO, B.: El Corregidor... pp. 268-269. Una muestra de los conflictos de jurisdicción que se plantean entre el intendente-corregidor y los alcaldes, en Valencia, y sobre el «cursus» burocrático de estos últimos, en mi tesis Absolutismo y poder local..., pp. 155-222.

(35) AGS, Gracia y Justicia, leg. 800.

(36) Los informes de la Cámara de Castilla sobre el estado del Ayuntamiento de Valencia, y donde recomienda la reducción del número de regidores a 24, son de 1715 y 1732; el de la Audiencia es de 1721 (AHN, Consejos, leg. 18.351).

(37) Por Real Resolución de 4 de febrero de 1736 (AHN, Consejos, leg. 18.351).

(38) A pesar del número de regidores asignado al Ayuntamiento de Valencia, no todos ejercian en la práctica como tales. En 1738, la Audiencia, en un informe enviado a la Cámara de Castilla, con fecha de 4 de febrero, comunica que de las 16 plazas de la clase de caballeros, 8 estaban sin cubrir. Transcurridos algunos meses, el Capitán General y presidente de la Audiencia propone al monarca una lista de trece individuos, siete de ellos con título nobiliario, $\mathrm{y}$ «buenos», según sus propias palabras, para ocupar dichas vacantes. Advertía, además, que ninguno aceptaría el oficio de regidor «si no es con expreso mandato de V. M.», debido a «la falta de conocimiento con que otros lo pretenden, y algunos en quien ha sido demasiada osadía imaginarlo...» (AHN, Consejos, leg. 18.351).

(39) Por Reales Decretos de 30 de diciembre de 1738 y de 27 de enero de 1739 se autoriza la enajenación «de los oficios concernientes al gobierno político y económico de la Corona de Aragón». Posteriormente, por otro Real decreto de 10 de noviembre de 1741 , se revoca la venalidad de dichos oficios, pudiendo tantearlos los pueblos, pagando a los compradores lo que hubieran desembolsado por ellos; se exceptuaban las ciudades de Zaragoza, Valencia y Barcelona (Novísima Recopilación, Lib. VII. Tít. V. Ley IX. nota 1).

(40) AHN, Consejos, legs. 18.349 y 18.350.

(41) AHN, Consejos, legs. 18.349 y 18.350.

(42) Este aspecto puede verse en el capítulo II de mi tesis doctoral, Absolutismo y poder local..., pp. 223-592

(43) Para el municipio castellano, Domínguez Ortiz señala que «la mayoría de las ciudades se encontraron al terminar el siglo XVII sometidas a regidores propietarios del cargo y casi siempre nobles»; en Sevilla, Toledo, Córdoba, etc., este estamento monopolizaba los cargos locales (DOMÍNGUEZ ORTIZ, A.: Las clases privilegiadas en la España del Antiguo Régimen, Madrid, Itsmo. 1973, Cf. pp. 123, 124, 127 y 129).

(44) AGS, Gracia y Justicia, leg. 800.

(45) AHN, Consejos, leg. 18.353 (informe del Ayuntamiento, de 1765, a propósito de una plaza vacante de la clase de nobles).

(46) (A)rchivo (H)istórico (M)unicipal de (V)alencia, Primera B, C. 1, doc. núm. 7 (informe del Ayuntamiento, de 1769, a raiz de una vacante de la clase de ciudadanos).

(47) AHN, Consejos, leg. 18.353, (informe del Ayuntamiento, de 1769, a raíz de una vacante de la clase de ciudadanos).

(48) A lo largo del siglo XVIII tenemos constancia de dos propuestas en este sentido. La primera, del oidor de la Audiencia José Torán y Sorell, conde de Albalat, en un informe secreto remitido a la Cámara de Castilla, a petición de la misma, en 1745. En él se decía, entre otras cosas, que uno de los remedios a aplicar para evitar la entrada en el Ayuntamiento de gentes desconocidas era dejar de elegir regidores de la clase de ciudadanos (AHN, Consejos, leg. 18.352). La segunda, fue protagonizada por el Ayuntamiento, en 1792 (AHMV, Cartas Misivas, 1792-93, g-3/76, fols. 85-86).

(49) La Real Cédula de Luis I puede consultarse en MADRAMANY Y CALATAYD, M.: Tratado de la Nobleza...

(50) Ibid.

(51) AHMV, Cartas Misivas, 1792-93, g-3/76, fols. 85-86.

(52) La documentación consultada para elaborar este apartado es la siguiente: AHN, Consejos, leg. 18.351, 18.352 y 18.353; AGS, Gracia y Justicia, leg. 800; AHMV, Primera B, C.-1, doc. 
núm. 7; C. -2 , doc. núm. 22 ; c. -3 , docs. núms. $31,32,35$; C. -4 , docs. núms. 40, 43, 46, 52 y 53 ; c. -5 , docs. núms. $58,60,61,70,74$ y 89 ; c. -6 , doc. núm. 93.

(53) A partir de la documentación citada en la nota (52).

(54) ANES, G.: El Antiguo Régimen: los borbones, Madrid, Alianza Editorial, 1975; Id.: Economía e "Ilustración" en la España del siglo XVIII, Barcelona, Ariel, 1981.

(55) AHMV, Primera B, C. -4, docs. núms. 40, 43 y 46; C. -5, doc. núm. 60.

(56) AHMV, Primera B, C.-5, doc. núm. 89.

(57) Los informes citados en AHN, Consejos, leg. 18.351 y 18.352.

(58) AHN, Consejos, leg. 18.351.

(59) AHN, Consejos, leg. 18.351.

(60) AHN, Consejos, leg. 18.351.

(61) AHN, Consejos, leg. 18.351.

(62) AHN, Consejos, leg. 18.352.

(63) AHN, Consejos, leg. 18.352.

(64) La información sobre los salarios de los regidores la hemos obtenido de los Reglamentos de rentas de la ciudad: Reglamento que deverá observarse en la Administración y distribución de los Caudales de Propios, Rentas y Arbitrios de la ciudad de Valencia, Madrid, 24/12/1767; Reglamento que deberá observarse en la Administración y distribución de las Rentas de Propios y Arbitrios que disfruta la Ilustre Ciudad de Valencia, sujeto al primitivo Reglamento que en el año de 1767 prefinió el Consejo á la misma Ilustre Ciiudad, con demostración de su actual estado según las Reales Resoluciones y Decretos expedidos desde dicho año de 1767 hasta el día que han originado su alteración, Valencia, 16/12/1801.

(65) Estos requisitos en ningún momento aparecen de forma explícita, sino que se desprenden de los varios informes elaborados por el Ayuntamiento a raiz de las vacantes. Dichos informes se encuentran en la documentación citada en la nota (52).

(66) Esta cuestión se dio casi en los mismos términos en Salamanca, donde el Ayuntamiento, a la altura de 1789, elevó el mínimo de renta exigible de 5.000 a 12.000 reales, Cf., INFANTE MIGUELMOTTA, J.: El municipio de Salamanca a finales del antiguo Régimen. Contribución a su estudio institucional, Salamanca, Ayuntamiento de Salamanca, 1984, p. 47.

(67) Novisima Recopilación, Lib. VIII. Tít. XXIII. Ley VIII.

(68) Novísima Recopilación, Lib. VII, Tít. XVIII. Ley. III.

(69) Cf., GARCÍA MONERRIS, E.: Absolutismo y poder local..., pp. 436-441.

(70) AGS. Gracia y Justicia, leg. 800.

(71) Para estos datos hemos utilizado, igualmente, las fuentes citadas en la nota (52).

(72) AGS, Gracia y Justicia, leg. 800 y leg. 1. AHN, Consejos, leg. 18.351.

(73) AHN, Consejos, leg. 18.349 y 18.350.

(74) En 1745, tres miembros de la Audiencia, entre ellos el conde de Albalat, informaban de forma reservada al monarca sobre las razones que, desde su punto de vista, inducian a la nobleza del «Reino» a inhibirse del gobierno de la ciudad. Tales razones pueden resumirse en dos: el exceso de autoridad conferida a los intendentes-corregidores, $y$ la venta de los oficios de regidor. La enajenación había permitido, según el conde, el acceso al Ayuntamiento de «gentes incognitas, cuyos padres no pensaron llegar a sentarse en aquellos bancos» (AHN, Consejos, leg. 18.352). Ello hizo que el oficio de regidor se mirara con «desprecio y tedio» por parte de la «principal nobleza de este Pueblo», según palabras del propio intendente-corregidor (carta del intendente-corregidor al Presidente del Consejo, de 17/3/1745. AHN, Consejos, leg. 18.352).

En el reciente libro de Gabriele Ranzato se observan cuáles fueron las razones en virtud de las cuales también en el siglo XIX se dio cierto abstencionismo en el ejercicio de los cargos municipales. Las circunstancias distintas que rodean a los ayuntamientos en plena sociedad liberal no excluyen, sin embargo, la relativa similitud existente entre un poder exterior presuntamente omnímodo (el Estado, representado por la primera autoridad provincial) y una autoridad local limitada (el alcalde y los 
ayuntamientos). V́éase: RANZATO, G.: La aventura de una ciudad industrial. Sabadell entre el Antiguo Régimen y la modernidad. Barcelona, Península, 1987, pp. 90 ss.

(75) Una nueva oligarquía, y con ella una nueva nobleza, ocuparía, predominantemente, los cargos de regidor. La adquisición de sus títulos nobiliarios es reciente, entre mediados del siglo XVIII y principios del siglo XIX: José Vicente Ramón de Cascajares será barón de Tamarit desde marzo de 1768 (AHMV, Libros Capitulares, 1768, ses. 7/5/1768); Francisco Pascual Castillo Izco y Quincoces, marqués de Jura Real desde noviembre de 1760 (AHMV, Libros Capitulares, 1760, ses. 27/11/1760); Bartolomé Musoles y Pastor obtiene el título de barón de Campolivar en 1778 (AHMV, Libros Capitulares, 1778, ses. 31/10/1778); Ignacio Llopis Ferris ostentará el de conde de la Concepción a partir de 1790 (AHMV, Libro I de Registro de Reales Privilegios de Nobleza, h-3, fols. 291-295); Vicente Merita y Albornoz donó su plaza de regidor perpetuo al monarca a cambio del título de barón de Uxola, en 1799 (AHMV, Libro II Registro de Reales Privilegios de Nobleza, h-3/28, fols. 108-112); Manuel María Giner y Giner recibiría el título de barón de San Vicente y Giner en 1804 (AHN, Consejos, leg. 18.354); y Bernardo Bertodano y Narváez sería marqués del Moral aproximadamente desde la década de los setenta (AHN, Consejos, leg. 18.352).

El caso particular del barón de Santa Bárbara, ennoblecido desde 1799 , lo tratamos más ampliamente en GARCÍA MONERIS, E. y SERNA ALONSO, J.: «Los orígenes sociales de la élite moderada en Valencia. El ejemplo del barón de Santa Bárbara», en prensa. En dicho artículo nos extendemos en el análisis de la familia Rodríguez de la Encina desde principios del siglo XVIII hasta la década de los sesenta del XIX. Cómo fundamenta esta dinastía su poder económico y cómo se vincula posteriormente al bloque moderado valenciano constituyen el eje central de lo abordado. 